2nd International Conference on Ultrafine Grained \&

Nanostructured Materials (UFGNSM)

International Journal of Modern Physics: Conference Series

Vol. 5 (2012) 18-23

(C) World Scientific Publishing Company

DOI: $10.1142 / \mathrm{S} 2010194512001791$

\title{
MICROSTRUCTURAL AND MECHANICAL CHARACTERIZATION OF CONSOLIDATED NANO- AND MICRON- SIZE Cu POWDERS
}

\author{
A. SALEH \\ School of Metallurgy and Materials Engineering, University of Tehran, \\ Tehran, P.O. Box: 14395-553, Iran \\ asra.saleh@gmail.com \\ S. HESHMATI-MANESH \\ School of Metallurgy and Materials Engineering, University of Tehran, \\ Tehran, P.O. Box: 14395-553, Iran \\ sheshmat@ut.ac.ir \\ A. ATAIE \\ School of Metallurgy and Materials Engineering, University of Tehran, \\ Tehran, P.O. Box: 14395-553, Iran \\ aataie@ut.ac.ir \\ S. SHEIBANI \\ School of Metallurgy and Materials Engineering, University of Tehran, \\ Tehran, P.O. Box: 14395-1491, Iran \\ sheibani_s@engmail.ut.ac.ir
}

\begin{abstract}
In this paper, nano-crystalline $\mathrm{Cu}$ powder with a mean crystallite size of $45 \mathrm{~nm}$ and commercial micron-size $\mathrm{Cu}$ powder were either hot pressed or cold pressed and sintered conventionally to fabricate bulk samples. Hardness, density, crystallite size and microstructure of the samples after consolidation were examined. The results show that the hardness of the hot pressed nano-crystalline $\mathrm{Cu}$ is in the range of $0.75-1.2 \mathrm{GPa}$ which is higher than that of commercial $\mathrm{Cu}$. The density of the bulk nano-crystalline sample showed that the rising sintering temperature increases the density up to $97 \%$ of the theoretical value. The mean crystallite size of the hot pressed sample was $64 \mathrm{~nm}$, which still was in the nano scale. The scanning electron microscopy (SEM) images revealed that the hot pressed samples contain less porosities compared to the conventionally consolidated samples.
\end{abstract}

Keywords: Nano-crystalline; Hot pressing; Copper.

\section{Introduction}

Nano-crystalline materials have received a great deal of attention over the past years. These materials are potentially attractive for many applications since the reduction of the 
grain size to the nanometer scale can improve their physical and mechanical properties ${ }^{1}$. It was found that the physical properties of $\mathrm{Cu}$ are directly contributed by the grain size. For instance, Yang et al. $^{2}$ have reported that $\mathrm{Cu}$ with a smaller grain size can exhibit unique mechanical behavior. Besides, Qian and $\mathrm{Lu}^{3}$ recently reported the optical and electrical properties of $\mathrm{Cu}$ to be strongly depended on the volume of grain boundaries. Therefore, it is of the great significance to control the grain size of $\mathrm{Cu}$ compacts thorough the sintering procedure.

Different methods are available to avoid the accelerated grain growth associated with densification and, therefore, provide fine microstructures. To achieve near full density, we must apply artificial pressure to overcome the energy barrier to combine the powders. Particular consolidation techniques, such as hot pressing or spark plasma sintering provide the driving force for densification ${ }^{4}$.

In this work, consolidation of nano-crystalline $\mathrm{Cu}$ prepared by mechano-chemical reduction of copper oxide with carbon ${ }^{5}$, was investigated. Consolidation parameters were studied carefully to identify their influences on hardness, density and grain growth of the prepared specimens.

\section{Experimental Procedure}

Nano-crystalline $\mathrm{Cu}$ with an mean crystallite size of $45 \mathrm{~nm}$ was synthesized by mechanochemical reduction of copper oxide with carbon ${ }^{5}$. The nano-crystalline synthesized powder together with a micron-size powder were hot pressed under a pressure of $70 \mathrm{MPa}$ using cylindrical graphite dies with an inner diameter of $15 \mathrm{~mm}$ thickness of $4 \mathrm{~mm}$. The hot pressing was carried out in a temperature range of 500 to $800{ }^{\circ} \mathrm{C}$ for 1 hour. The heating rate was $10^{\circ} \mathrm{Cs}^{-1}$. For conventional cold pressing and sintering experiment, the powder was uniaxially cold pressed at $160 \mathrm{MPa}$ into pellets with the same dimensions. They were sintered in a tube furnace under argon atmosphere. The sintering condition i.e. temperature range, heating rate and sintering time were chosen similar to those of the hot pressing experiment.

The morphology and phase identification of the products were examined by SEM (Cam Scan MV2300) and XRD (Philips Xpert pro) using a Co $\mathrm{k}_{\alpha}$ radiation $(\lambda=1.78892$ $\AA$ ), respectively. The mean crystallite size of the specimens was calculated using Williamson-Hall plot $^{6}$. The density measurements of the specimens were made based on Arachimedes principle. The Vickers microhardness measurements were taken on each specimen. 


\section{Results and Discussion}

XRD patterns of the nano-crystalline powder before and after consolidation are shown in Fig. 1. These patterns show only the peaks of $\mathrm{Cu}$ phase. A magnified part of the patterns clearly reveals that peaks of nano-crystalline powder are broader than consolidated samples. This is obviously due to re-crystallization, grain growth and the release of residual strains in the particles at high temperatures.
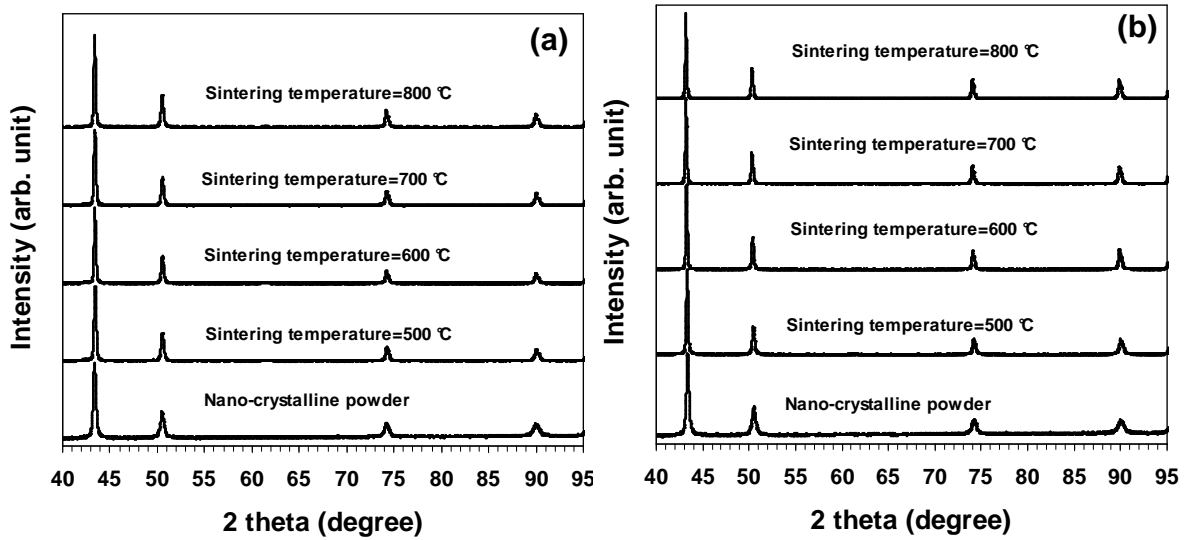

Fig. 1. XRD patterns of (a) the conventionally consolidated and (b) hot pressed nano-crystalline $\mathrm{Cu}$.

Fig. 2 shows dependence of the density of the consolidated samples to the mean crystallite size obtained by hot pressing and conventional consolidation routes. It shows that in both sintering methods a crystallite growth rate and density increment occurs in the stage of consolidation. It is interesting to note that the consolidated sample prepared by conventional method indicates a finer crystallite size comparing to the one prepared by the hot pressing. However, the external pressure directly affects densification which is higher after hot pressing. As seen in Fig. 2, hot pressing has been capable to produce specimens with a density as high as $97 \%$ of the theoretical bulk copper density comparing the density obtained by the conventional consolidation which is $87 \%$ of the theoretical value.

Fig. 3 shows density changes of the consolidated samples as a function of the sintering temperature. Samples prepared from the micron-size powder shows a higher density comparing with the nano-crystalline samples. This is probably due to the much more insoluble gas entrapped in the pores of the nano-crystalline powder. At high temperatures, an increase in the gas pressure entrapped in the pores may prohibit the mass transport caused by the diffusion mechanisms ${ }^{7}$. Also easy plastic deformation of the micron-size $\mathrm{Cu}$ leads to higher densification. As seen in Fig. 3, sintering behavior of the nano-crystalline $\mathrm{Cu}$ during hot pressing in its last stage is quite like the micron-size $\mathrm{Cu}$. 


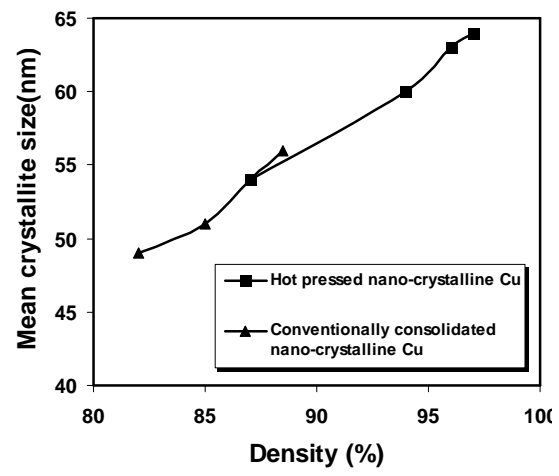

Fig. 2. Mean crystallite size of the hot pressed and conventionally consolidated nano-crystalline $\mathrm{Cu}$ as a function of density.

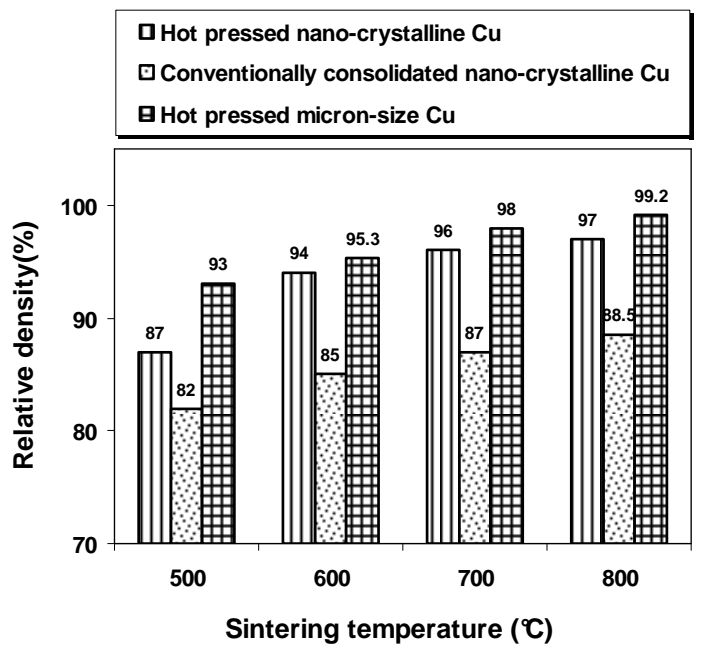

Fig. 3. Density of the hot pressed and conventionally consolidated nano-crystalline $\mathrm{Cu}$ and hot pressed micronsize $\mathrm{Cu}$ as a function of sintering temperature.

Fig. 4 shows variations of the hardness in the consolidated samples as a function of sintering temperature. The highest hardness value was obtained in the nano-crystalline $\mathrm{Cu}$ hot pressed at $500{ }^{\circ} \mathrm{C}$. While the hot pressing condition for both micron and nanocrystalline $\mathrm{Cu}$ powder was the same. Fig. 4 shows that rising temperature decreases the hardness of both nano-crystalline $\mathrm{Cu}$ samples but it has an opposite effect on the hardness of the micron-size samples. Increase of density and decrease of porosity in the micron samples has positive effect on the increasing of hardness ${ }^{8}$. In the nano-crystalline samples dislocation density decreases by increasing temperature and its softening effect is much more dominant comparing with the hardening effect of decreasing porosities. 
Fig. 5 shows typical SEM images of the hot pressed samples prepared from nanocrystalline and micron-size powders. The initial impression from these images is that higher sintering temperature results in more dense samples with compact structures. Fig. 5(a)-(c) show that the size and density of the pores reduces and agglomerates of nanosized powder coalescence to each other and their boundaries disappear when the temperature rises up.

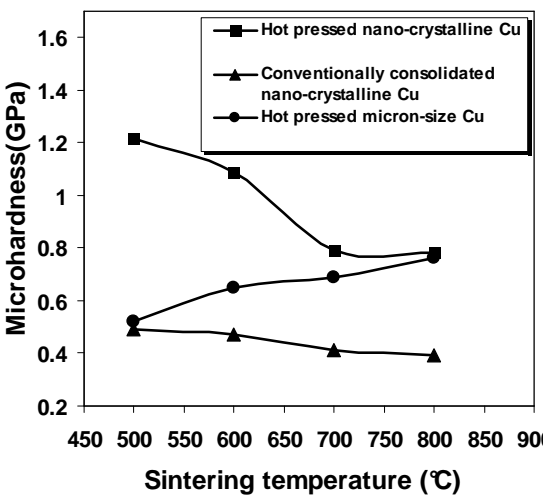

Fig. 4. Hardness of the hot pressed and conventionally consolidated nano-crystalline $\mathrm{Cu}$ and hot pressed micron-size $\mathrm{Cu}$ as a function of sintering temperature.


Fig. 5. SEM images of the hot pressed (a-c) nano-crystalline $\mathrm{Cu}$, (d-f) micron-size $\mathrm{Cu}$, at (a,d) 500; (b,e) 600; $(\mathrm{c}, \mathrm{f}) 700^{\circ} \mathrm{C}$. 


\section{Conclusions}

Sintering behavior of the nano-crystalline and micron-size $\mathrm{Cu}$ powder using hot pressing method was investigated and was compared to those obtained by conventional consolidation route. Density of the nano-crystalline $\mathrm{Cu}$ sample hot pressed at $800^{\circ} \mathrm{C}$ was $97 \%$ of the theoretical density. The sintering efficiency of hot pressing was higher than conventional method which could provide the maximum density. The micron-size $\mathrm{Cu}$ powder indicated to be more capable than the nano-crystalline one to get a closer density to the theoretical value ( $\geq 98 \%)$, though the applied pressure was exactly the same. Furthermore, rising temperature decreases the hardness in both nano-crystalline $\mathrm{Cu}$ samples produced by hot pressing and conventional consolidation but it has an opposite effect on micron-size powder.

\section{Acknowledgments}

The financial support of this work by the Iran Nanotechnology Initiative Council is gratefully acknowledged.

\section{References}

1. M. Mazaheri, S.A. Hassanzadeh-Tabrizi, S.K. Sadrnezhaad, Ceramics Int. 35, 991 (2009).

2. M.C. Yang, F. Ye, X.C. Sun, X.K. Sun, W.D. Wei, Nanostructured Mater. 9, 1997 (1997).

3. L.H. Qian a, Q.H. Lu a, W.J. Kong b, K. Lu a, A. Heidarpour, F. Karimzadeh, M. H. Enayati, Scripta Mater. 50, 1407 (2004).

4. A. Weibel, R. Bouchet, R. Denoyel, J. Eur.Ceram. 27, 2641 (2007).

5. S. Sheibani, A. Ataie, S. Heshmati-Manesh, G.R. Khayati, Mat. Let. 61, 3204, (2007).

6. G.K. Williamson, W.H. Hall, Acta Metall. 1, 22 (1953).

7. A.P. Hynes, R.H. Doremus, R.W. Siegel, J. Am. Ceram. 8, 1979 (2002).

8. C. C. Koch, Nano-structured Materials: Processing, Properties and Potential Applications (New York. Noyes Publications, 2002). 